\title{
A pedagogia dos multiletramentos e multiplicidade semiótica no texto infantil
}

\author{
Pedagogy of multiple types and semiotic multiplicity in children's text
}

\author{
Natany da Silva Avelar ${ }^{1}$ \\ Helena Maria Ferreira ${ }^{2}$
}

\begin{abstract}
Resumo
O presente artigo visa a discutir sobre possibilidades de uso de múltiplas semioses em retextualizações feitas por crianças em fase de alfabetização. Para tanto, o artigo traz estudos sobre o papel do professor alfabetizador no processo de produção de textos infantis e sobre os multiletramentos. O texto, que resulta de uma dissertação de mestrado, evidencia a abordagem dos textos infantis em uma perspectiva discursiva, que considera aspectos do processo dialógico do processo de alfabetização para além do estudo do sistema alfabético. Revela-se, com este estudo, que os recursos tecnológicos podem favorecer o processo de produção de textos infantis e contemplar a interação entre sociedade e escola.
\end{abstract}

Palavras-chave: Produção de texto; Multiletramentos; Formação docente

\begin{abstract}
This article aims to discuss the possibilities of using multiple semioses in retextualizations made by children in literacy. To this end, the article brings studies on the role of the literacy teacher in the process of producing children's texts and on the multi-tools. The text, which results from a master's thesis, highlights the approach of children's texts in a discursive perspective, which considers aspects of the dialogical process of the literacy process beyond the study of the alphabetical system. It is revealed, with this study, that technological resources can favor the process of producing children's texts and contemplate an interaction between society and school.
\end{abstract}

Keywords: Text production; Multiliteracies; teacher education

\section{Introdução}

Produzir textos com crianças ainda em fase alfabetização é um desafio que requer estratégias e condições adequadas para que a criança sinta-se impelida e motivada à produção,

\footnotetext{
${ }^{1}$ Mestre em Educação pelo Programa de Pós-graduação em Educação (mestrado profissional), pela Universidade Federal de Lavras, Lavras, MG, Brasil. E-mail: nathyavelar@gmail.com

${ }^{2}$ Doutora em Linguística, Professora do Departamento de Estudos da Linguagem (Universidade Federal de Lavras, Lavras, MG, Brasil. E-mail: helenaferreira@ufla.br
} 


\section{QO DEVIR EDUCAÇÃO}

ISSN: 2526-849X

mesmo ainda não tendo consolidado as habilidades de leitura e escrita. Nesse caso, os recursos multissemióticos podem contribuir para a promoção de um percurso alfabetizador que viabilize uma reflexão acerca da pluralidade semiótica que constitui os textos que circulam na sociedade da informação.

A escola é parte do meio social em que a criança vive e possibilita a qualificação das interações para a vida fora da escola. Em diversas situações sociais, os sujeitos são demandados a produzir textos, seja para deixar um bilhete, seja para contar algum acontecimento a outra pessoa, seja para gravar uma mensagem de áudio em um aplicativo de celular, seja para fazer uma postagem nas redes sociais digitais, o fato é que a produção textual está presente nas ações que realizamos cotidianamente, em diferentes modalidades (oral, escrita, imagética etc).

Nesse contexto, o professor alfabetizador, na atualidade, encara um desafio: distanciar-se das técnicas mecânicas de produção e avaliação das produções de textos e propiciar ações significativas de leitura e escrita que viabilizam a formação de sujeitosautores.

Além disso, a Base Nacional Comum Curricular elucida que:

Há que se considerar, ainda, que a cultura digital tem promovido mudanças sociais significativas nas sociedades contemporâneas. Em decorrência do avanço e da multiplicação das tecnologias de informação e comunicação e do crescente acesso a elas pela maior disponibilidade de computadores, telefones celulares, tablets e afins, os estudantes estão dinamicamente inseridos nessa cultura, não somente como consumidores (BRASIL, 2017, p. $57)$.

Considerando esses desafios e a multiplicidade de recursos semióticos existentes, com a expansão do uso das tecnologias digitais, buscou-se apresentar, neste artigo, uma das diversas possibilidades de colocar em prática a Pedagogia dos multiletramentos em situações de produção textual infantil, utilizando recursos digitais.

Não obstante, merece destacar que não existe receita pronta para o trabalho com os multiletramentos, mas, sim, possibilidades e caminhos diversos que podem contemplar as múltiplas culturas e a multiplicidade semiótica que pode constituir uma produção textual. Registra-se, aqui, uma delas, por acreditar que possa contribuir com estudos na perspectiva dos multiletramentos e com a prática profissional docente na contemporaneidade, pela reflexão sobre o uso de recursos tecnológicos nas práticas de produção de texto. 


\section{OO DEVIR EDUCAÇÃO}

ISSN: 2526-849X

\section{A produção de textos na perspectiva dos multiletramentos}

A produção de textos, desde o início da alfabetização, seja por meio de tentativas de escrita individual, seja por meio de produções coletivas, oportuniza tanto a autonomia progressiva quanto à contextualização das formas de organização e de funcionamento dos textos escritos. Um aluno que aprende a produzir textos desde cedo, de forma gradual e prazerosa, provavelmente, terá menos dificuldades nas diversas situações sociais que demandarem uma produção escrita.

A produção de textos, na atualidade, permite o uso de muitos recursos além das palavras. Inclusive, os portadores de textos também são diversos, incluindo plataformas digitais. Isso significa dizer que o leitor e o escritor precisam compreender e saber utilizar os diversos recursos multissemióticos que possibilitam produções cada vez mais amplas e diversificadas.

Dado o exposto, reitera-se que não há apenas um caminho metodológico para tornar a criança uma leitora e produtora de textos, mas, sim, um rizoma - conceito baseado nos estudos do filósofo Deleuze e Guatari (1995), ou seja, vários caminhos interligados.

Um rizoma não começa nem conclui, ele se encontra sempre no meio, entre as coisas, inter-ser, intermezzo. A árvore é filiação, mas o rizoma é aliança, unicamente aliança. A árvore impõe o verbo "ser", mas o rizoma tem como tecido a conjunção "e... e... e..." Há nesta conjunção força suficiente para sacudir e desenraizar o verbo ser (DELEUZE; GUATTARI, 1995, p. 35).

Cabe refletir que o processo de aprendizado da língua é um processo contínuo, que se inicia no princípio da vida e que não se encerra até o fim dela, uma vez que, o processo de aprendizagem contempla várias dimensões linguísticas, semióticas e discursivas, que acabam por emprestar complexidade às propostas de alfabetização em uma perspectiva interacionista.

Esse contexto rizomático e dialógico do processo de alfabetização, que precisa articular o domínio do sistema linguístico-semiótico e o domínio discursivo, impõe um tratamento mais amplo à alfabetização, que contemplará as múltiplas situações de uso de diferentes linguagens, o que acaba por contemplar o conceito de multiletramentos.

Ao analisar o termo multiletramentos, é relevante partir, inicialmente, do conceito de letramento. De acordo com Soares (2001), o termo letramento traduz para o português a palavra inglesa litteracy. Letramento possui um significado amplo, vai além da alfabetização, 


\section{OO DEVIR EDUCAÇÃO}

ISSN: 2526-849X

pois, não caracteriza apenas a técnica de codificação (escrita) e decodificação (leitura) de símbolos, mas, representa uma condição, um resultado de ação de ensino ou aprendizagem de leitura e escrita envolvido nas práticas sociais.

Nesse sentido, considerando a multiplicidade de semioses (palavras, imagens, cores, sons etc.) e os usos sociais que contribuem para o processo de produção de sentidos dos textos que circulam no cotidiano social, é necessário implicar o conceito de multiletramentos.

Como revela Roxane Rojo, esse conceito

aponta para dois tipos específicos e importantes de multiplicidade presentes em nossas sociedades, principalmente urbanas, na contemporaneidade: a multiplicidade cultural das populações e a multiplicidade semiótica de constituição dos textos por meio dos quais ela se informa e se comunica. (2012, p.13).

Nessa perspectiva, é preciso reiterar que a sociedade contemporânea possui diversos e diferentes recursos midiáticos e constitui-se de uma geração envolvida com a tecnologia. Os multiletramentos, então, consubstanciam a pluralidade cultural e a multiplicidade de linguagens textuais, valorizando, assim, a realidade e o repertório social dos discentes.

Em situações sociais em que os textos aparecem cada vez mais produzidos com diversas possibilidades semióticas (áudio, imagem, movimento, palavras, etc.), faz-se importante levar para o âmbito escolar ações em que as propostas de produção textual contemplem essa realidade e que os textos produzidos pelos discentes possam fazer parte da circulação real desses tipos de textos multissemióticos. Assim, é apropriado que a produção infantil não seja realizada apenas para o domínio do sistema de escrita, mas que os textos de autoria das crianças possam ser veiculados em portadores específicos às suas particularidades e alcancem diferentes interlocutores - não apenas o docente - a fim de provocar uma situação de ensino-aprendizagem significativa.

É importante atentar-se para os novos e múltiplos letramentos e as novidades tecnológicas como parceria de trabalho docente e não como vilãos. Souza $(2015, \mathrm{~s} / \mathrm{p}$.) confirma que "a pedagogia dos multiletramentos não veio contrapor as ações docentes, mas, contribuir nas suas sistematizações; as novas tecnologias digitais veem mudando nossos hábitos tanto pessoais, quanto institucionais". Não é possível ignorar os avanços tecnológicos e suas influências no contexto escolar. É válido reiterar que nenhuma criança chega à fase de alfabetização sem algum contato com ações de leitura e escrita e as tecnologias que as envolvem. Ferreiro (2010) comenta que as crianças “(...) iniciam o seu aprendizado do 


\section{QO DEVIR EDUCAÇÃO}

ISSN: 2526-849X

sistema de escrita nos mais variados contextos, porque a escrita faz parte da paisagem urbana, e a vida urbana requer continuamente o uso da leitura (p. 95)".

Assim, o professor alfabetizador tem um papel além de importante para o encaminhamento de práticas pedagógicas que podem favorecer a ampliação de habilidades relacionadas ao ensino de línguas na perspectiva dos multiletramentos. No entanto, essa perspectiva impõe desafios. Delia Lerner expõe que um dos principais desafios

é conseguir que as crianças manejem com eficácia os diferentes escritos que circulam na sociedade, e cuja utilização é necessária ou enriquecedora para a vida (pessoal, profissional, acadêmica), em vez de tornarem especialistas nesse gênero exclusivamente escolar que se denomina "composição" ou "redação" (LERNER, 2002, p.28).

Para a promoção de interações com os diversos gêneros que circulam no cotidiano social, outro desafio se impõe: a formação docente para o trabalho com textos multissemióticos, que implica considerar os diferentes recursos que contribuem para o processo de produção de sentidos.

Nessa direção, não basta promover espaços para a leitura de textos com diferentes semioses, é necessário incentivar a criação de textos, cuja produção evoca escolhas de recursos e sistemas sígnicos e uma análise de seus efeitos de sentido. Assim, por se tratar de uma situação de alfabetização, cabe ao professor atuar como intérprete da produção de textos dos alunos, buscando compreender suas escolhas e seus modos de conceber a organização e o funcionamento dos textos. Nessa direção, é relevante pontuar que o professor, ao se colocar na posição de intérprete da produção da criança, não pode considerar apenas o que é o esperado. A produção infantil não corresponderá a um resultado idealizado/esperado como homogêneo. É interessante refletir sobre a questão da demanda da escola - a criança deve corresponder, deve responder 'corretamente' à demanda que lhe é feita e se não o faz, 'está errado". A produção da criança é tomada a partir do ponto de vista do produto, o que torna irrelevante o processo de construção de conhecimentos/saberes. No entanto, sob o ponto de vista dialógico, a criança está entre textos (falados/escritos/lidos), distante do diálogo e da demanda do outro - professor e, também da tarefa proposta. Na fase de alfabetização, o processo de produção de sentido se efetiva por meio das tentativas de uso da modalidade verbal escrita (palavras, frases, textos), de uso da modalidade verbal oral (diálogos com pares e professor), de uso de imagens (desenhos, cores etc). Assim, ao se colocar na posição de 


\section{QO DEVIR EDUCAÇÃO}

ISSN: 2526-849X

intérprete ou de escriba da criança, o professor pode contribuir para que as crianças percebam que suas ideias podem assumir formas e transformar-se em escrita constituída e produzir sentidos. Assim, a articulação entre as diferentes semioses será constitutiva do processo de aquisição/aperfeiçoamento dos saberes sobre a língua/linguagem e também das (inter)subjetividades (professor e aluno).

\section{Análise de uma experiência de formação docente}

Para ilustrar a pesquisa teórica, esta seção é constituída por uma análise de uma experiência de produção textual realizada por um aluno do $1^{\circ}$ ano do Ensino Fundamental (início da alfabetização escolar) de uma escola pública municipal em Lavras - MG. Essa experiência contou com o desenvolvimento de um projeto de intervenção, que teve por objetivo a produção de textos, a partir de um texto-base (retextualização). Para a coleta de dados foi utilizado o instrumento de diário de campo, em que foram registrados dados que serviram de base para a análise realizada.

Considerando os limites deste artigo, será analisado apenas um episódio dessa experiência. O percurso de produção contou com três momentos: a) leitura do conto pela professora; b) retextualização do texto lido por parte das crianças (individualmente); c) seleção de um texto das crianças para retextualização para uma versão digital, com a participação da turma toda de $1^{\circ}$ ano do Ensino fundamental, explorando-se recursos semióticos e com o apoio de um profissional da tecnologia.

A retextualização que será analisada, a seguir, teve como texto-base o seguinte conto:

\section{Cinderela}

Cinderela era filha de um comerciante rico. Depois que seu pai morreu, sua madrasta tomou conta da casa que era de Cinderela. Cinderela então, passou a viver com sua madrasta malvada, junto de suas duas filhas que tinham inveja da beleza de Cinderela e transformaram-na em uma serviçal. Ela tinha de fazer todos os serviços domésticos e ainda era alvo de deboches e malvadezas. Seu refúgio era o quarto no sótão da sua própria casa e seus únicos amigos: os animais da floresta.

Um belo dia, é anunciado que o Rei realizará um baile para que o príncipe escolha sua esposa dentre todas as moças do reino. No convite, distribuído a todos os cidadãos, havia o aviso de que todas as moças deveriam comparecer ao Baile promovido pelo Rei.

A madrasta de Cinderela sabia que ela era a mais bonita da região, então disse que ela não 
poderia ir porque não tinha um vestido apropriado para a ocasião. Cinderela, então, costurou um vestido com a ajuda de seus amigos da floresta. Passarinhos, ratinhos e esquilos a ajudaram a fazer um vestido de retalhos, mas muito bonito. Porém, a madrasta não queria que Cinderela comparecesse ao baile de forma alguma, pois sua beleza impediria que o príncipe se interessasse por suas duas filhas. Sendo assim, ela e as filhas rasgaram o vestido, dizendo que não tinham autorizado Cinderela a usar os retalhos que estavam no lixo. Fizeram isso de última hora, para impedir que a moça tivesse tempo para costurar outro.

Muito triste, Cinderela foi para seu quarto no sótão e ficou à janela, olhando para o Castelo na colina. Chorou, chorou e rezou muito. De suas orações e lágrimas, surgiu sua Fadamadrinha que confortou a moça e usou de sua mágica para criar um lindo vestido para Cinderela. Também surgiu uma linda carruagem e os amiguinhos da floresta foram transformados em humanos, cocheiro e ajudantes de Cinderela. Antes de sua afilhada sair, a Fada-madrinha lhe deu um aviso: a moça deveria chegar antes da meia-noite, ou toda a mágica iria se desfazer aos olhos de todos.

Cinderela chegou à festa como uma princesa. Estava tão bonita, que não foi reconhecida a não ser pela madrasta, que passou a noite inteira dizendo para as filhas que achava conhecer a moça de algum lugar, mas não conseguia dizer de onde. O príncipe quando a viu, logo a convidou para dançar. Cinderela e o príncipe dançaram e dançaram a noite inteira. Conversaram e riram como duas almas gêmeas e logo se perceberam feitos um para o outro.

Acontece que a fada-madrinha tinha avisado que toda a magia só duraria até à meia-noite e um. Quando o relógio badalou as doze batidas e um minuto, Cinderela teve de sair correndo. Foi quando deixou um dos seus sapatinhos de cristal na escadaria. O príncipe, muito preocupado por não saber o nome da moça ou como reencontrá-la, pegou o pequeno sapatinho e saiu em sua busca no reino e em outras cidades. Muitas moças disseram ser a dona do sapatinho, mas o pé de nenhuma delas se encaixava no objeto.

Quando o príncipe bateu à porta da casa de Cinderela, a madrasta trancou a moça no sótão e deixou apenas que suas duas filhas experimentassem o sapatinho. Apesar das feiosas se esforçarem, nada do sapatinho de cristal servir. Foi quando um ajudante do príncipe viu que havia uma moça na janela do sótão da casa.

Sob as ordens do príncipe, a madrasta teve de deixar Cinderela descer. A moça então experimentou o sapatinho, mas antes mesmo que ele servisse em seus pés, o príncipe já tinha dentro do seu coração a certeza de que havia reencontrado o amor de sua vida. Cinderela e o príncipe se casaram e foram felizes para todo o sempre.

Quadro 3: Conto Cinderela 
Após ler a história Cinderela, a professora solicitou a retextualização do conto, sugerindo modificações do enredo, mas mantendo a personagem principal.

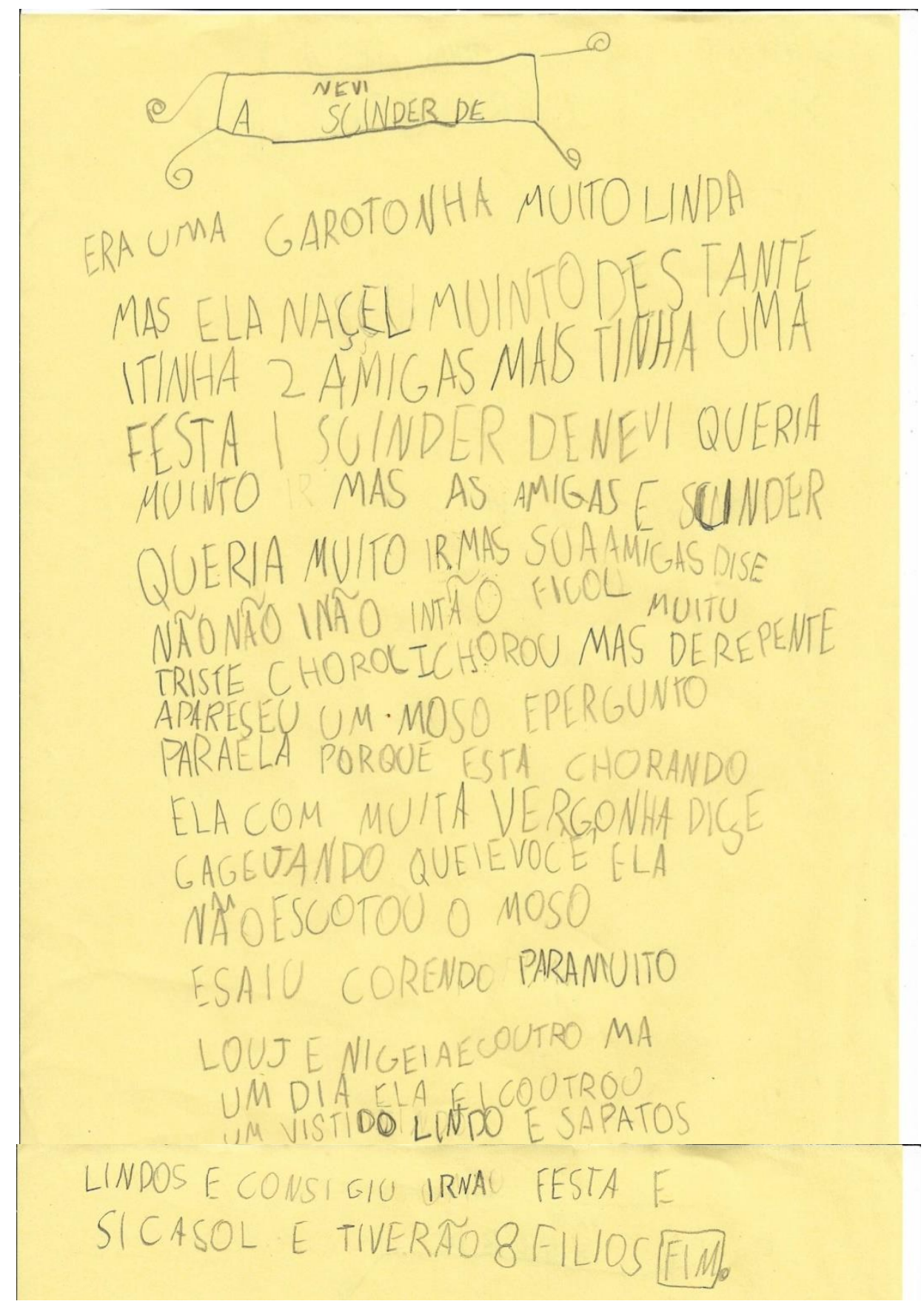

Figura 2: Produção escrita: Cinderela

Fonte: Produção do aluno P.

Data: $21 / 08 / 18$

No episódio da figura 2, observa-se que a criança atende à solicitação, embora sua escrita seja caracterizada por uma produção que ainda apresenta marcas de uma fase de 


\section{QO DEVIR EDUCAÇÃO}

ISSN: 2526-849X

apropriação do sistema linguístico. Assim, ainda é possível encontrar troca de letras (garotonha/garotinha, naçel/nasceu, escotou/escutou), hipercorreções (destante/distante, ficol/ficou), junção vocabular (derepente/de repente, sicasol/se casou), marcas da oralidade (intão/então, muinto/muito), entre outras "incorreções", que demonstram uma escrita singular e que sustentam o processo de produção de sentidos. O movimento interpretativo do texto da criança está veiculado ao olhar do leitor, uma vez que o funcionamento dos textos e, por extensão, da linguagem se efetiva por meio da interação entre os interlocutores. Se a interpretação implica sempre "uma tensão entre reconhecimento e estranhamento" (PEREIRA DE CASTRO, 1995) dos arranjos inusitados e das conquistas evidenciados nos textos produzidos pelas crianças, é relevante que o adulto (professor, pais, etc.) perceba na escrita da criança um saber sobre/da língua.

Nesse processo de retextualização, a criança busca estabelecer relações lógicas entre fonemas e grafemas (apareseu/apareceu), apresentar construções sintáticas próprias da língua constituída (era uma garotonha muito linda mas ela naçel muinto destante.../ era uma garotinha muito linda, mas ela nasceu muito distante...) e seguir a constituição peculiar das composições narrativas (personagens, enredo, delimitadores iniciais e finais, fala de personagens, verbos no passado, etc.).

Nesse sentido, a atividade de retextualização, com todas as (des) articulações presentes na materialidade textual, propicia a instauração de uma escrita autoral, aqui evidenciada pela inserção de falas de personagens (não não i não/ não, não e não) e pela proposição de um novo final (e tiveram 8 filios/ e tiveram 8 filhos). Assim, o texto-base e sua história de amor se inscreve na produção da criança, o que evidencia que mesmo sendo uma narrativa que reconta a história lida, ela é um texto de alguém. A retextualização representa a possibilidade de a criança ser arrebatada por outra história, iluminando "a presença subjacente da estrutura sobre a qual se move o sujeito que dá sustentação ao texto" (LEMOS, M. T. 1992, p.134). A escrita da criança des/revela uma posição ativa, que é inerente a interpretação de outros textos. Esses outros textos incorporados aos saberes da criança possibilitam novas relações, novos efeitos de sentido.

Desse modo, os erros, as construções enigmáticas e os distanciamentos das instruções passadas às crianças devem ser tolerados e interrogados, uma vez que essas questões integram o processo de entrada da criança na escrita, ou seja, são inevitáveis e constitutivas (FERREIRA, 2008). 


\section{OO DEVIR EDUCAÇÃO}

ISSN: 2526-849X

Complementando o exposto, Mota (1995) postula que a interação com textos orais e escritos possibilita a dinamização do processo de aquisição da escrita, seja para compreender a organização/funcionamento peculiar dessa modalidade, seja para a criança se deslocar em relação à própria fala e adentrar-se no universo da escrita. Essas modalidades apresentam similaridades, mas também diferenças que lhe são constitutivas. A criança que escreve é um sujeito já constituído e em constituição pela linguagem.

Na produção da criança, é possível constatar a presença de elementos do texto-base: a personagem é bonita, queria participar de uma festa, conhece um rapaz, "ganha" um vestido e sapatos lindos, vai a uma festa e se casa. Esses elementos evidenciam a relevância do outro que com quem a criança interage (professor, colegas, autores das histórias e a própria criança) para a constituição da linguagem. Pela relação com o outro, a criança se constitui como sujeito da/na linguagem, num constante movimento dialógico. Para Bakhtin (2011, p. 300),

uma visão de mundo, uma corrente, um ponto de vista, uma opinião sempre têm expressão verbalizada. Tudo isso é discurso do outro (em forma pessoal ou impessoal), e este não pode deixar de refletir-se no enunciado. $\mathrm{O}$ enunciado está voltado não só para seu objeto, mas também para os discursos dos outros sobre ele.

Nessa perspectiva, a produção da criança, influenciada pelo outro, responde a uma demanda da escola (ou do professor), que, de certo modo, impõe determinadas construções. Assim, a criança faz uso de itens lexicais, tais como "destante" e "derepente", que são mais usuais nos discursos que figuram em textos escritos. Esses exemplos, embora possam aparentar uma estratégia discursiva recorrente, evidenciam escolhas que se originam do textobase. Normalmente, a criança utiliza termos sinônimos, como "longe" e "aí" nas suas narrativas orais. O emprego da hipercorreção "destante" indicia um movimento de construção da escrita por parte da criança, assim como a junção vocabular "derepente". É a criança "mostrando" a sua marca no texto.

Desse modo, os discursos, que naturalizam ou justificam uma posição de um não saber por parte da criança em fase de aquisição da escrita, (des)velam um desconhecimento por parte do professor de que os sujeitos-aprendizes ocupam uma posição enunciativa na atividade de escrita. "A escrita é, assim, um espaço a mais, importantíssimo, de manifestação da singularidade dos sujeitos" (ABAURRE, FIAD, MAYRINK-SABINSON, 1997, p.23).

Registra-se também que ao ocupar o papel de intérprete do texto da criança, merecem destaque as ocorrências sinalizadoras dessa singularidade e de suas influências na construção 


\section{QO DEVIR EDUCAÇÃO}

ISSN: 2526-849X

do projeto de dizer. Assim, questões como a nomeação da personagem principal "Scinder de nevi" e a substituição da versão tradicional "foram felizes para sempre" por "sicasol e tiverão 8 filios" evidenciam discursos outros que incorporados pela criança são transformados e tomados como referência para o sujeito em constituição, que num constante movimento toma a palavra do outro para torná-la palavra própria.

Ao realizar a retextualização digital, a professora fez opção pelo trabalho coletivo. Assim, a partir da produção retextualizado pelo aluno P., ela foi disponibilizando três alternativas de imagens para que as crianças da turma escolhessem a cena mais apropriada ao conteúdo da história. Nesse contexto, as escolhas eram justificadas a partir de argumentos apresentados pelas crianças, conforme se observa a seguir.

Inicialmente, as crianças escolheram uma personagem para ser a componente principal da história. Foram expostas três opções para escolha: Uma mulher, uma menina (criança) e uma princesa. A professora releu o início da história do aluno P. e questionou qual seria a melhor escolha. Nesse momento, algumas meninas gostariam de ter escolhido a princesa, porém foram contestadas pelo próprio autor da produção textual que disse: “- A história diz que era uma garotinha muito linda e não uma princesa" (Excerto do diário de campo). Vários alunos, incluindo algumas meninas que haviam votado na princesa para compor a personagem principal, concordaram e a professora questionou se todos estavam de acordo ou se queriam escolher outra personagem. As crianças concordaram que a menina da foto abaixo seria a melhor escolha para a personagem e seguiram com as propostas de cenários e situações com o decorrer da história. 


\section{OO DEVIR EDUCAÇÃO}

ISSN: 2526-849X

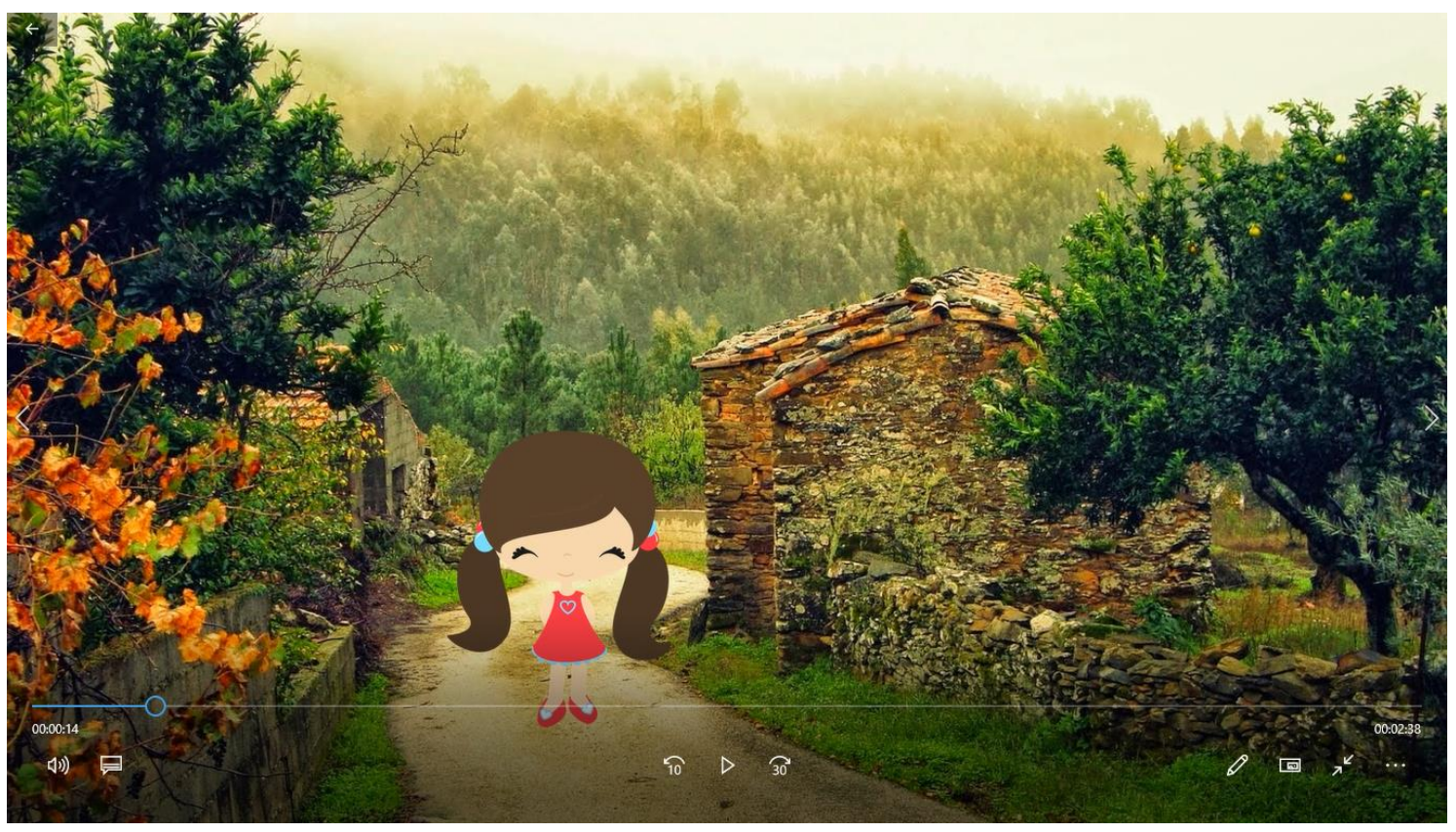

Figura 3

Retextualização digital: Scinder de Nevi

Arquivo pessoal

Na figura 3, as crianças relacionaram um lugar distante com o cenário desprovido de movimento de pessoas, com a presença de casas em ruínas e mata fechada. Assim, as escolhas realizadas pelos alunos possibilitam a mobilização de conhecimentos relacionados às diferentes modalidades (oral, escrita, imagens) "para expressar-se e partilhar informações, experiências, ideias e sentimentos em diferentes contextos e, com eles, produzir sentidos que levem ao entendimento mútuo". (ROJO; MOURA, 2012, p. 21). Essa inserção das múltiplas linguagens do contexto da alfabetização possibilita um trabalho pautado na perspectiva dos multiletramentos, conforme concebido por Rojo (2009).

Para a autora a leitura e a produção de textos em diversas linguagens e semioses (verbal, oral e escrita, musical, imagética, corporal e do movimento) possibilita a formação de leitores críticos e éticos, nas diversas práticas do cotidiano social. Nesse sentido, o trabalho de retextualização torna-se um espaço privilegiado de análises das múltiplas linguagens que constituem os textos que circulam na sociedade da informação, uma vez que viabiliza a discussão sobre os diferentes modos de produção de sentidos e promove espaços de usos das diversas linguagens, expressas em diversos sistemas semióticos (ou sígnicos). Essa atividade se configura como uma prática de linguagem, portanto, é um lugar de interação humana, interação comunicativa pela produção de efeitos de sentido entre interlocutores (GERALDI, 


\section{OO DEVIR EDUCAÇÃO}

ISSN: 2526-849X

2009). Nessa abordagem, os sujeitos utilizam a linguagem não só para a troca de conhecimentos, mas também para agir, atuar sobre o outro e sobre o mundo.

$\mathrm{Na}$ figura 4, observa-se que as estratégias utilizadas pelas crianças evidenciam a mobilização de conhecimentos prévios sobre a linguagem e seus usos.

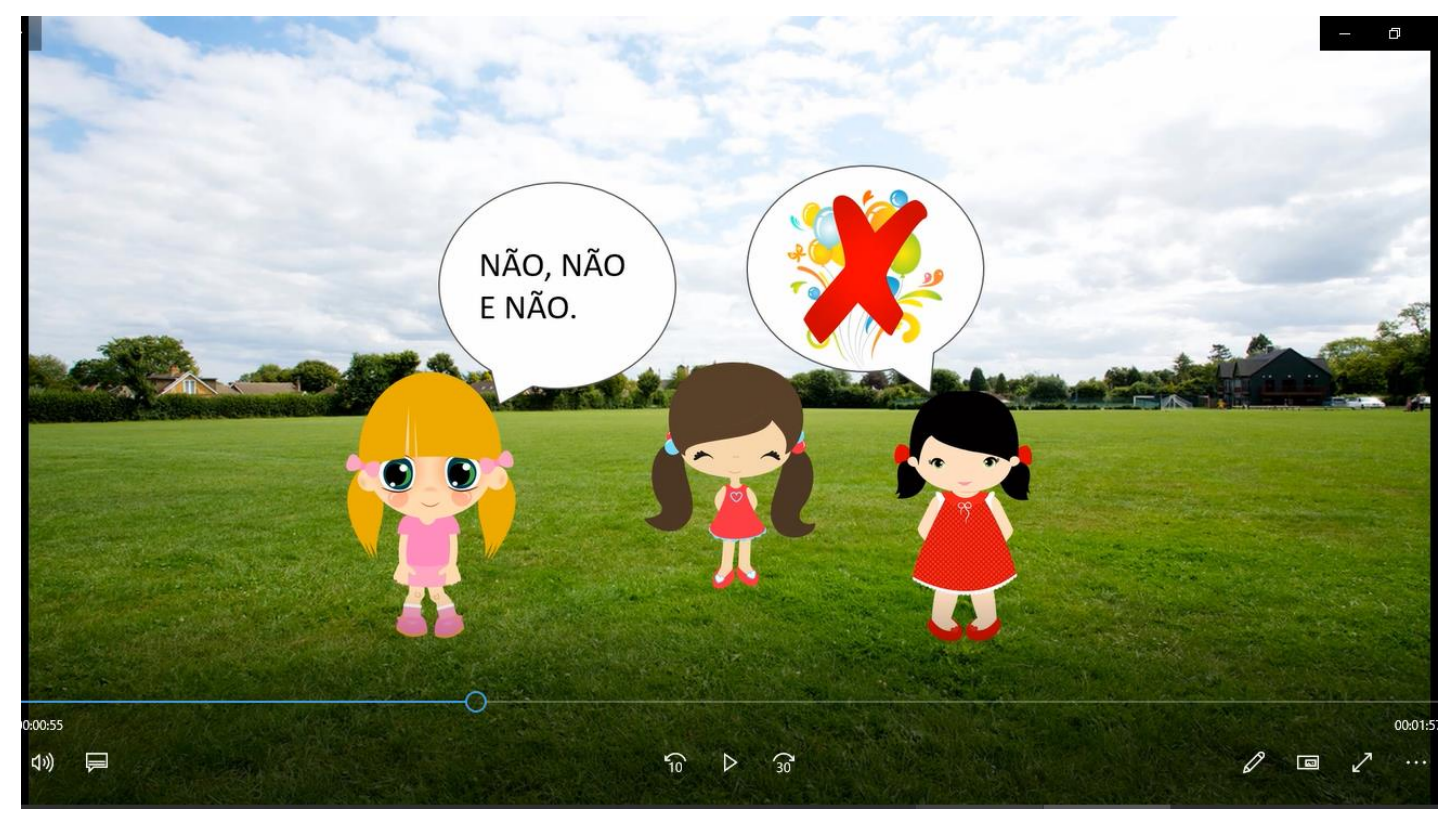

Figura 4

Retextualização digital: Scinder de Nevi Arquivo pessoal

Após a escolha do cenário, a aluna I. chama a atenção dizendo: "Nessa hora, tinha que ter um balãozinho com as amigas falando não para Scinder de Nevi”. A professora, nesse momento, acata a sugestão da aluna e questiona: "Como poderíamos fazer isso?". Alguns alunos levantam as mãos para dar suas opiniões e o aluno R. sugere: "Igual aqueles balões de história em quadrinhos", o aluno D. complementa: "A gente pode escrever dentro do balão não, não e não" e a aluna A. fala: "Ou então um desenho de festa, tipo umas bexigas e um $\mathrm{X}$ vermelho, que vai significar que a Scinder de Nevi não pode ir”. Nessa ocasião, a professora não tinha esse tipo de opção pronta no computador para mostrar e pediu para que a aluna desenhasse em um papel o que havia imaginado. A aluna A., então, esboçou em uma folha o desenho de bexigas de festas sendo encobertas por um $\mathrm{X}$ grande, que a aluna fez com lápis de cor vermelho, por cima dos balões apenas desenhados com lápis de lição. (Excerto do diário de campo).

A opção pela conjugação de uso de balões com texto verbal "não, não e não" e com uma metáfora visual "balões (bexigas) indicando festa e o X indicando negação" evidencia 


\section{OO DEVIR EDUCAÇÃO}

ISSN: 2526-849X

que a apropriação da linguagem na alfabetização não se limita a aprendizagem do código verbal. Nesse sentido, a retextualização insere-se em um outro contexto, que envolve outros sujeitos, com outros saberes, outros tempos e outros espaços. Assim, segundo Geraldi (2009) dar contexto a um texto significa analisá-lo sobre uma outra perspectiva, é colocá-lo em diálogo com outros textos. É analisar as múltiplas semioses tecidas na unidade do acontecimento de enunciados concretos e únicos, participam desse aqui e agora único, desse momento singular. Desse modo, a reiteração do item lexical "não" indicia uma marca do discurso oral que é representado por meio de um balão de fala. Soma-se a isso, a escolha dos balões (bexigas) para representar a ideia de festa e do símbolo convencional X para evidenciar a ideia de negação. Essa escolha evidencia processos de interação de sujeitos, que se constituem na e pela linguagem, a partir de suas relações com o mundo e com o outro.

Por fim, na figura 5, a construção da imagem pelas crianças suscita possibilidades interpretativas.

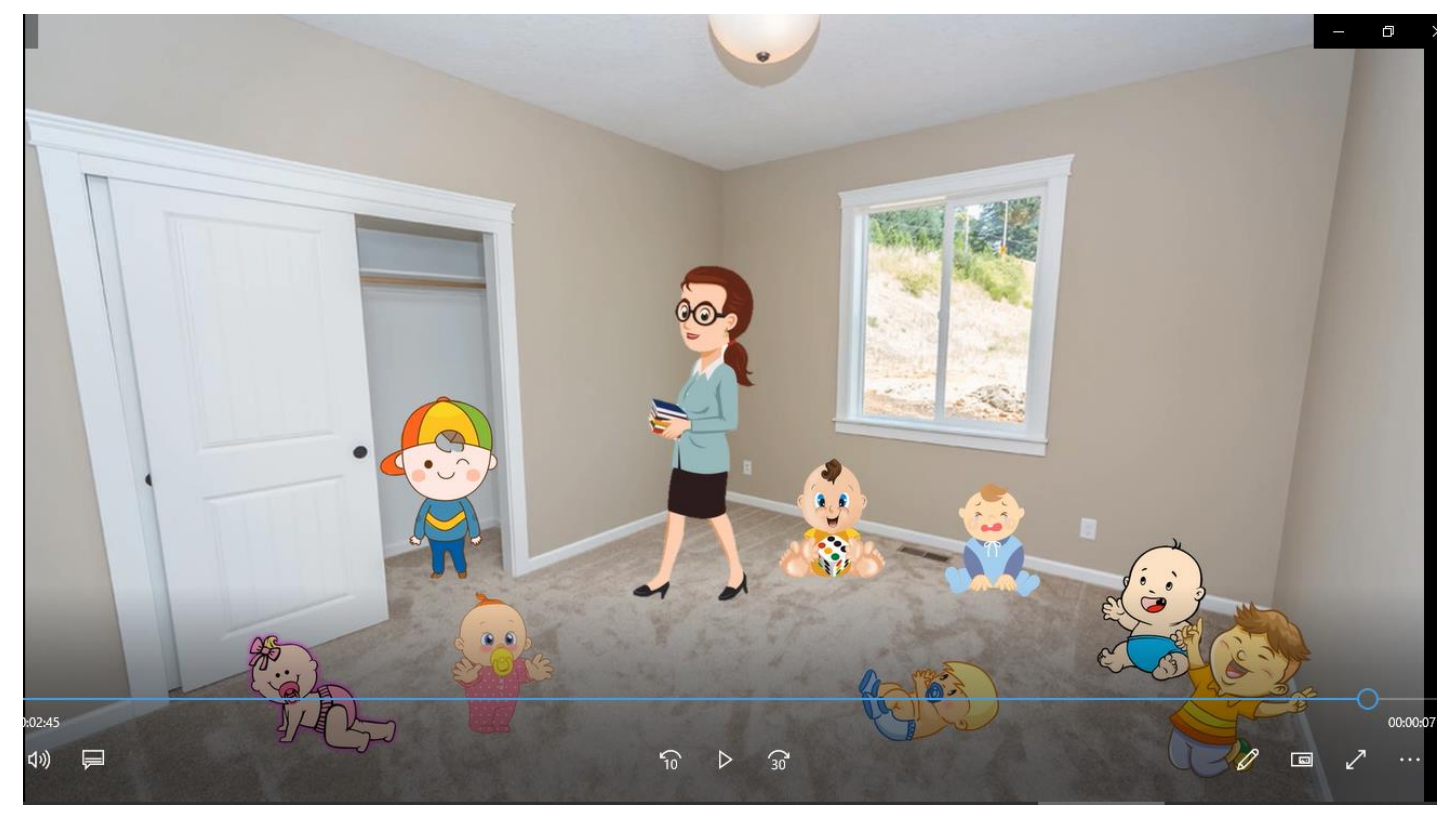

Figura 5

Retextualização digital: Scinder de Nevi

Arquivo pessoal

Na figura em pauta, a representação da "princesa" se distancia das escolhas anteriores: ela aparece mais velha, com cabelo preso, com óculos e com uma roupa social, o que parece sugerir a ideia de mãe. A intenção de escolher uma outra opção de personagem para o final da história surgiu das próprias crianças, o aluno D. disse: "não pode mais ser uma menina, ela já cresceu". Nesse instante, a professora pergunta: "O que faremos, então? Temos as opções que 


\section{QO DEVIR EDUCAÇÃO}

ISSN: 2526-849X

escolhemos no início, vamos vê-las novamente?” Mas, a aluna M. sugere: "procura, na internet, uma mãe" e a professora segue a sugestão buscando imagens no Google, na opção vetor. "Essa parece com a Scinder mais velha" indica o aluno P. (autor da produção escrita) e os demais colegas concordam (Excerto do diário de campo). Além disso, os alunos colocam em destaque as 8 crianças em um espaço fechado, sem móveis. Nesse momento da retextualização, embora a cena evidencie o conteúdo da parte final da história, as escolhas realizadas sinalizam para outras possibilidades interpretativas, "o que é trazido, repetido do texto do outro, vem com diferença, pois passa pela interpretação do sujeito" (ASPILICUETA, 2014, p.113), ou seja, as crianças ao transmutarem o texto da modalidade oral (leitura) e da modalidade escrita pelo aluno P. para o texto audiovisual deixam pistas para leituras outras. Essas possibilidades de leitura abrem caminho para a atuação do professor, que cumpre o papel do outro tutelar (BORGES, 2016), que considera que a entrada da criança na escrita não deve ser em uma posição de espectadora. Não é a proposta da aula em si que forma o aluno produtor de texto, mas as interações que são estabelecidas nela.

No tocante à oralização do texto para articulação com as imagens, a professora realizou uma discussão com os alunos acerca das partes do texto que deveriam corresponder a cada cena. Essa construção coletiva acerca dos movimentos de articulação entre as diferentes semioses (oral, escrito e imagético) promoveu deslocamentos não só em relação às perspectivas das crianças no processo de produção de sentidos, mas também em relação aos modos de efetivação da prática pedagógica, uma vez que o trabalho sistematizado com as múltiplas linguagens se constitui como uma atividade que imprime muitos desafios.

Além das dificuldades inerentes à inserção de práticas que contemplem o estudo de textos multissemióticos e a retextualização em sala de aula, a posição de intérprete, atribuída ao professor, também se configura como uma ação que se reveste de complexidade. A leitura realizada pelo aluno P., o mesmo autor da retextualização escrita, evidencia um sujeito em constituição, que se alterna entre um saber fazer e um saber em construção (o texto produzido encontra-se disponível em https://tecalf.blogspot.com/2018/09/scinder-de-neve.html). Na mesma leitura, as pausas, a pronúncia das palavras, a entonação, o ritmo fazem emergir "erros" e "acertos", demonstrando que o professor precisa considerar a aquisição da linguagem como um processo não cumulativo, mas sujeito a idas e vindas, a reelaborações e reestruturações (ABAURRE, FIAD, MAYRINK-SABINSON, 1997). Para as autoras referenciadas, a oscilação entre usos adequados e inadequados representa um indício de que a 


\section{QO DEVIR EDUCAÇÃO}

ISSN: 2526-849X

criança está construindo saberes sobre a linguagem e, simultaneamente, produzindo referências e sentidos pelo e no discurso.

As montagens das imagens com as escolhas das crianças e a produção do vídeo final dessa retextualização digital contaram com o trabalho de um profissional ligado à área de tecnologias e informática.

\section{Considerações finais}

O presente artigo buscou problematizar o processo de produção de textos na alfabetização, destacando a perspectiva dos multiletramentos e o trabalho com as diferentes semioses em atividades de retextualização. A partir do trabalho realizado, constatou-se que a produção de textos com alunos que ainda não dominam a escrita pode parecer um desafio, porém, é uma atividade completamente possível e que possibilita o desenvolvimento de habilidades linguístico-discursivas, autonomia escrita, proficiência leitora e pode ser um meio para demonstrações de evidências subjetivas, promovendo, portanto, um processo de aquisição da escrita e da leitura emancipatório.

Foi possível verificar, ainda, que o trabalho com recursos tecnológicos e o contato com textos multissemióticos favorecem o estreitamento dos laços entre ações escolares e ações sociais, contribuindo para uma (re)significação do processo de ensino e de aprendizagem da produção de textos na escola. Considerou-se que os estudos realizados oportunizaram a compreensão de que, ainda que os recursos tecnológicos sejam escassos na educação básica pública, é possível desenvolver ações pedagógicas que propiciam o desenvolvimento de habilidades linguístico-semiótico-discursivas e o trabalho com os multiletramentos, por meio da retextualização digital.

Em face do exposto, ressalta-se que o desenvolvimento dessa pesquisa pode contribuir para a formação de professores, uma vez que apresenta uma reflexão acerca da produção de textos transformada em retextualizações digitais, à luz de teorias que podem favorecer o encaminhamento de práticas de ensino mais reflexivas. Nesse sentido, as ações didáticas realizadas e as reflexões acerca delas, aqui descritas e analisadas, permitem perceber percursos de possibilidades e estratégias pedagógicas que podem ser considerados caminhos para a realização de retextualizações digitais com crianças em fase de alfabetização. A proposta deste artigo foi a de discutir situações didáticas que possibilitam que o professor 


\section{OO DEVIR EDUCAÇÃO}

ISSN: 2526-849X

reflita sobre sua prática e amplie suas concepções sobre o processo de produção textual multissemióticos e sobre a utilização de recursos tecnológicos como aliados desse processo.

Desse modo, é fundamental que mais pesquisas sejam desenvolvidas nessa perspectiva e que professores possam ser motivados a desenvolver trabalhos que envolvam textos multissemióticos, uso de recursos digitais e, até mesmo, produções de texto desde o ingresso da criança na alfabetização, porque a ampliação de repertório pessoal e o contato precoce com variadas semioses podem auxiliar o processo de aquisição da leitura e da escrita.

\section{Referências}

ABAURRE, M. B. M.; FIAD, R. S.; MAYRINK-SABINSON, M. L. (1997). Em busca de pistas. Cenas de aquisição de escrita: o trabalho com o texto. Campinas, SP: Associação de Leitura do Brasil (ABL), Mercado de Letras (Coleção Leituras no Brasil):13-49.

ASPILICUETA, P. Movimento de Subjetivação da Criança na Escrita de Textos: entre o texto do outro e o texto próprio. 2014. 140 f. Tese (Doutorado) - Curso de Programa de Pósgraduação em Letras, Universidade Federal do Paraná, Curitiba, 2014.

BAKHTIN, M. Palavra própria e palavra outra na sintaxe da enunciação. A palavra na vida e na poesia: introdução ao problema da poética sociológica. Org. e equipe de trad. V. Miotello. São Carlos: Pedro \& João Editores, 2011.

BORGES, S. O quebra-cabeça: a alfabetização depois de Lacan. Ed. da Universidade Católica de Goiás, 2006.

BRASIL. Ministério da Educação. Secretaria da Educação Básica. Base nacional comum curricular. Brasília, DF, 2017. Disponível em: <http://basenacionalcomum.mec.gov.br/download-da-bncc/>. Acesso em: nov/2018.

DELEUZE, G.; GUATTARI, F. Mil platôs: capitalismo e esquizofrenia. Vol. 1. Rio de Janeiro: 34, 1995.

FERREIRA, H. M. Lição de casa: considerações sobre a relação criança/escrita.

Tese de Doutorado, Pontifícia Universidade Católica de São Paulo, São Paulo, 2008.

FERREIRO, E. Reflexões sobre alfabetização. 25. ed. São Paulo: Cortez, 2010.

GERALDI, J. W. Linguagem e ensino: exercícios de militância e divulgação. São Pauo: Mercado das Letras, 2009.

LEMOS, M. T. G. de. Sobre o que faz texto: uma leitura de Cohesion in English. Delta: Documentação de Estudos em Línguística Teórica e Aplicada, São Paulo, v.8, n.1, p.21-42, 1992. 
LERNER, D. Ler e escrever na escola: o real, o possível e o necessário. Porto Alegre: Artmed, 2002.

MOTA, S. B. V. O quebra-cabeça da escrita: a instância da letra na aquisição da escrita. São Paulo: 1995. 271 f. Tese (doutorado) - Psicologia da Educação, Pontifícia Universidade Católica de São Paulo, PUCS. 1995.

OLIVEIRA, E. C. Autoria: a criança e a escrita de histórias inventadas. Maceió: EDUFAL, 1998.

PEREIRA CASTRO, M. F. Ainda a negação: indo mais além na interpretação. Cadernos de Estudos Lingüísticos (UNICAMP), Campinas, v. 29, p. 27-38, 1995

ROJO, R. Pedagogia dos multiletramentos: diversidade cultural e de linguagens na escola. In: ROJO, R.; MOURA, E. (org). Multiletramentos na Escola. São Paulo: Parábola Editorial, 2012.

ROJO, R.; MOURA, E. (org). Multiletramentos na Escola. São Paulo: Parábola Editorial, 2012.

SOARES, M. Letramento: Um tema em três gêneros. Belo Horizonte: Autêntica, 2001.

SOUZA, I. V. de. Multiletramentos e práticas pedagógicas. Rev. Artefactum, v.15, n.2, 2015. 